\title{
INFECTIOUS DISEASES, NSW: JUNE 1999
}

\section{TRENDS}

Reports of infectious diseases were largely unremarkable for this time of year (Figure 3 and Table 2).

\section{NOTIFICATION OF TYPHOID}

On 8 June, the Victorian Department of Health reported a case of typhoid in a man who had been ill since 30 May. Later that evening the Western Sydney Public Health Unit (WSPHU) reported that a man from Western Sydney had been diagnosed with typhoid, and the Victorian Department of Health Department reported another case in a woman.

Typhoid is caused by infection with the bacteria Salmonella typhi which, after an incubation period of generally one to three weeks, results in an illness characterised by headache, fever, malaise, abdominal pain, nausea, diarrhoea or constipation, vomiting and cough. The bacteria are spread via the faecal-oral route, mainly by consuming contaminated food or water, or through contact with infected persons.

All three cases reported cruising on a ship operated by Company P that had left Cairns on 12 May, visited Port Moresby, then some Pacific Islands, and finished in Sydney on 25 May. There were some 950 passengers from across Australia and New Zealand, and about 450 crew on board.

While in Port Moresby, 159 passengers and crew took an 8-hour land tour to the Kokoda Trail, stopping at an inn for a lunch that included chicken, beef, pork, coleslaw, fruit, cake, iced water, and coffee. Over the few days following the tour, 105 passengers and 15 crew reported sick with diarrhoea to the ship's doctors. All 120 people who became ill had been on the Kokoda Trail tour, while none of the other passengers reported sick. The cause of this outbreak remains unclear.

Company P provided a list of all passengers, as well as a list of ill people seen by the ship's doctors. The NSW Department of Health (and other state and territory health departments) mailed a letter to all passengers outlining these events, advising them to see a doctor if they became sick and, if they had been on the Kokoda Trail tour, to call their local public health unit. Public health unit staff telephoned passengers who went on the Kokoda Trail tour to:

- advise them of the situation

- administer a questionnaire about their health and exposures while on the trip

- seek stool and urine samples from them for testing.
The public was alerted through media releases.

South Eastern Sydney Public Health Unit (SESPHU) is coordinating the NSW response to this outbreak. SESPHU staff inspected the ship, but no likely source of the outbreak was identified on board. It is probable that the initial outbreak of illness and the typhoid outbreak were caused by different organisms acquired from the same source in Papua New Guinea.

A national team including staff from the Commonwealth Department of Health and Aged Care, the State Departments of Health, and the Master of Applied Epidemiology Program of the National Centre for Epidemiology and Population Health (ANU) is coordinating an epidemiological investigation aimed at confirming the extent of the outbreak and its likely source. In NSW, public health unit staff have interviewed 65 Kokoda Trail tour participants and arranged for at least one stool sample to be tested from 62 of these.

To date, 12 cases of typhoid (including six from NSW) have been identified among persons who were on the cruise and visited the Kokoda Trail. Investigations continue.

\section{NSW INFUENZA SURVEILLANCE UPDATE}

\section{Rob Menzies}

Summary

Influenza activity continued at moderate levels for most of June; however, both laboratory reporting and clinical activity increased markedly in the last week of the month.

\section{Clinical activity}

Rates of influenza-like illness showed an increase in the last week of June, reaching a level similar to that for the same time in 1998 (Figure 4). Reports were received weekly from 31 general practitioners (GPs) through four Public Health Units, including more than 3,200 consultations.

\section{Virological activity}

There was an overall increase in laboratory reports for all respiratory viruses in the last week of June, with the exception of influenza B (Figure 5). The laboratory reporting rate for influenza $A$ increased markedly in the last week of June to a level higher than for the same period last year. There were 50 cases of influenza A reported (36 virological, 14 serological), one case of influenza B (virological), and 129 of respiratory syncytial virus (RSV). In the same week last year, there were nine cases of influenza A, none of influenza B and 168 of RSV.

\section{Directed virological surveillance}

In the last week, 43 nasopharyngeal swabs were received from 15 GPs. Eight tested positive for influenza A. No 


\section{FIGURE 3}

REPORTS OF SELECTED INFECTIOUS DISEASES, NSW, JANUARY 1994 TO MAY 1999, BY MONTH OF ONSET

These are preliminary data: case counts in recent moths may increase because of reporting delays cases
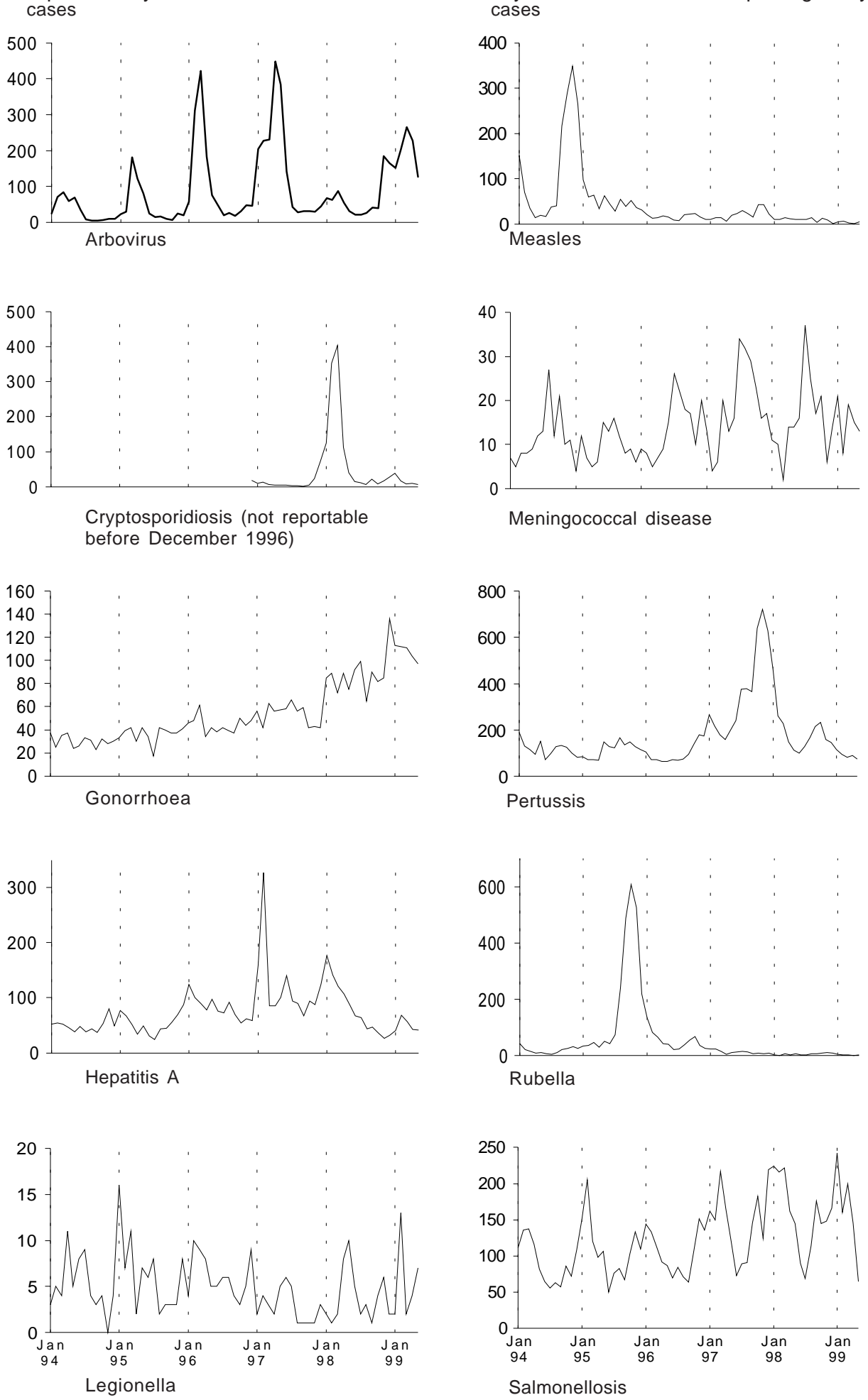


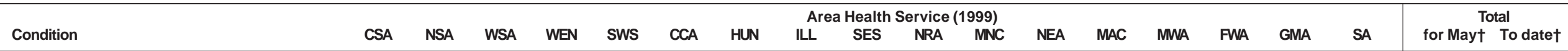

Blood-borne and sexually transmitted

AIDS HIV infection*

Hepatitis B: acute viral*

Hepatitis B: other

Hepatitis C: acute viral

Hepatitis D: unspecified*

Hepatitis, acute viral (not otherwise specified)

Chancroid*

Chlamydia (genital)*

Gonorrhoea

Syphilis

Vector-borne

Malaria*

Zoonoses
Brucellosis*

Leptospirosis

$Q$ fever

CSA NSA WSA WEN SWS CCA HUN

ILL SES NPA

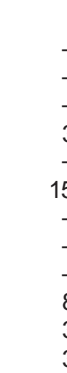

Respiratory and othe

Blood lead level ${ }^{*}$

Leprosy

Meningococcal infection (invasive)

Mycobacterial tuberculosis

Mycobacteria other than TB

Vaccine-preventable

Adverse event after immunisation

$H$. influenzae B infection (invasive)*

Measles
Mumps*

Pertussis

Rubella*

Tetanus

Faecal-oral

Botulism
Cholera*

Cryptosporidiosis*

Giardiasis*

Food-borne illness (not otherwise specified)

Gastroenteritis (in an institution)

Haemolytic uraemic syndrome

Hepatitis $A^{*}$

Hepatitis $\mathrm{E}^{*}$

Salmonellosis (not otherwise specified)

Typhoid and paratyphoid ${ }^{*}$

Verotoxin-producing E. coli

* lab-confirmed cases only

CSA = Central Sydney Area

$\mathrm{NSA}=$ Northern Sydney Area

WSA $=$ Western Sydney Area

nknown postcode

$\begin{array}{rrrr}- & - & - & 2 \\ - & - & - & 3 \\ - & - & - & - \\ 6 & 10 & 6 & 42 \\ - & - & - & - \\ 45 & 69 & 28 & 92 \\ - & - & - & 1 \\ - & - & - & - \\ - & - & - & - \\ 6 & 26 & 5 & 29 \\ 1 & - & - & 36 \\ - & - & - & 14\end{array}$




\section{FIGURE 4}

NSW GP SENTINEL SURVEILLANCE, INFLUENZA-LIKE ILLNESS (ILI), BY WEEK OF CONSULTATION, WITH HISTORICAL COMPARISONS
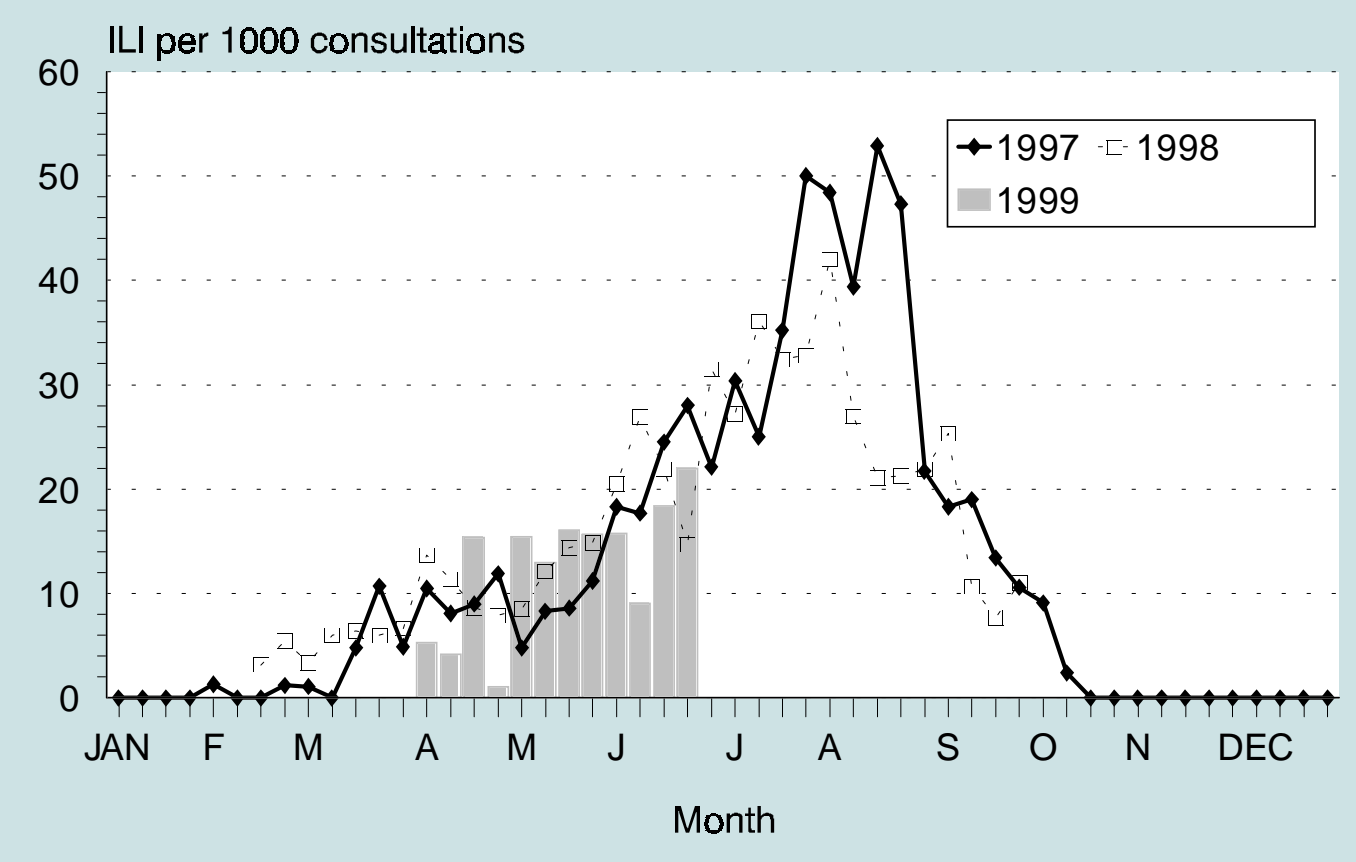

\section{FIGURE 5}

INFLUENZA VIRUS ISOLATION RATES, NSW, 1998-99

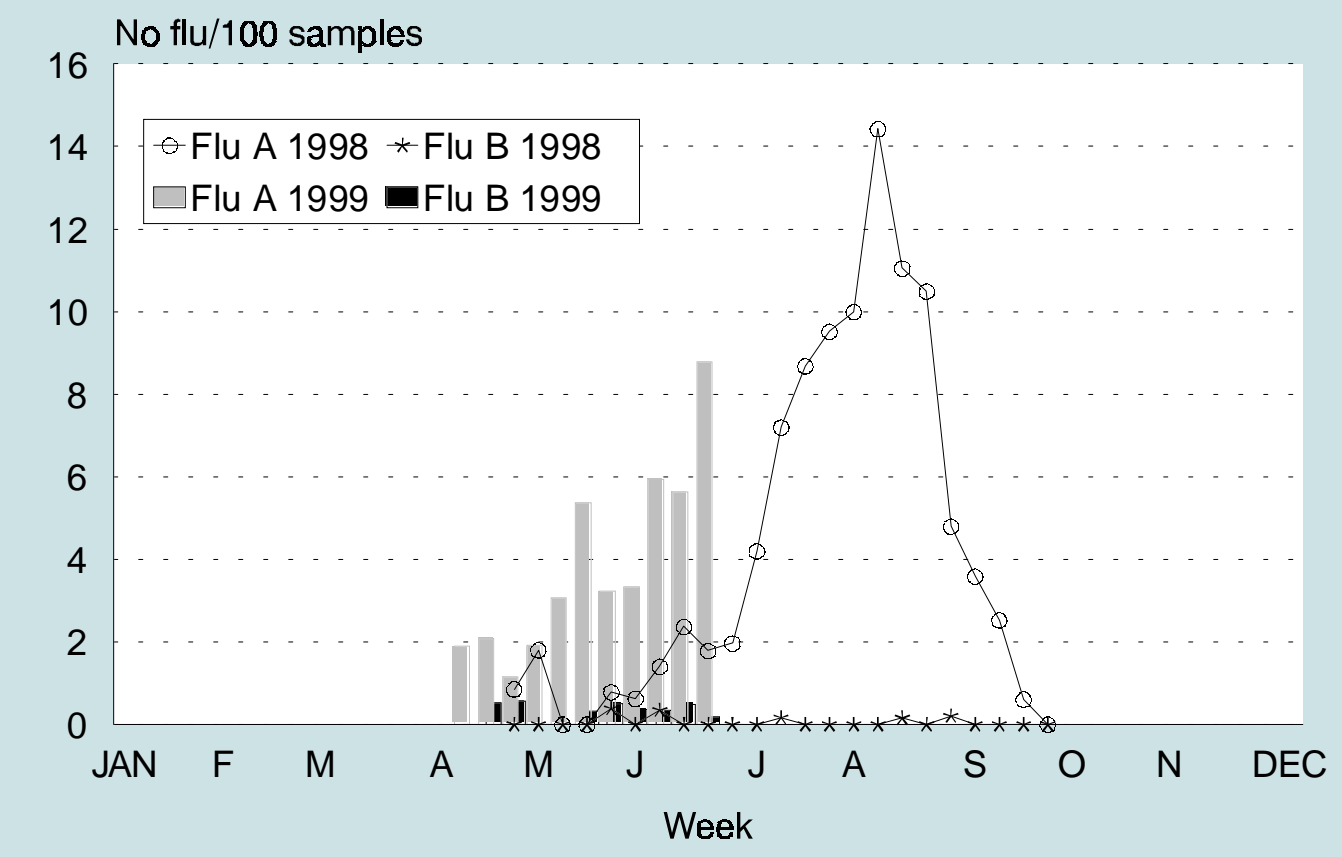


other respiratory viruses were reported. This represents an increase in the rate of isolation of viruses to 20 per cent from approximately 10 per cent over the past five weeks. Influenza A continues to be the predominant strain of influenza circulating in the community. Approximately 30 GPs from Central Sydney, South Eastern Sydney, Western Sydney, Wentworth, Central Coast, Hunter, Illawarra, Greater Murray and Southern Areas are participating in the surveillance scheme this year.

\section{International surveillance}

Brazil, South Africa, Argentina, New Zealand and New Calendonia reported influenza activity to the World Health Organization during June. Brazil reported a widespread outbreak of influenza A during early June which continues, while New Caledonia (Noumea) also reported influenza A. South Africa continues to report both influenza $\mathrm{A}(\mathrm{H} 3 \mathrm{~N} 2)$ and $\mathrm{B}$. Argentina reported a local outbreak of influenza. New Zealand also reported sporadic cases of influenza B and $\mathrm{A}(\mathrm{H} 3 \mathrm{~N} 2)$.

\section{Next issue}

The July issue of the NSW Public Health Bulletin will be the first in a series of two issues on injury surveillance and prevention. Articles include:

- Firearm injury and death in NSW

- Injury in rural and remote communities

- Childhood injury surveillance: The value of emergency department data

- Head injuries in infants: A closer look at babywalkers, stairs and nursery furniture

- NSW Injury Prevention Network contact and mailing list

- Families First: A support network for families raising children.

\section{LETTER TO THE EDITOR}

\section{DEAR EDITOR}

I refer to the article by Margaret Ashwell in Vol. 8, No. 10, page 84, entitled 'Normal immunoglobulin (human): Indications and safety'.

The author correctly points out that intramuscular gammaglobulin may be used as prophylaxis for susceptible contacts if given early in certain infections. It should be pointed out that this strategy may also be used for pre-exposure prophylaxis (though active immunisation is to be preferred). The author recommends the use of intramuscular immunoglobulin for the prophylaxis of varicella zoster. However, as is pointed out in the next paragraph, a zoster immune globulin preparation is available and this is the agent the use of which should be advised for the purpose of preventing varicella zoster infection.

The author correctly points out that there has been no HIV transmission since the introduction of donor screening in 1985. It should be pointed out that there were no HIV transmissions associated with immunoglobulin products in this country prior to that date despite the fact there certainly would have been donors during that period who carried HIV.
The author correctly points out that there have been no known reports of transmission of hepatitis $\mathrm{C}$ associated with the use of the normal immunoglobulin product for IV use manufactured by CSL in Australia. However, I am aware of a case still undergoing investigation in which the only possible source of hepatitis $\mathrm{C}$ was intramuscular immunoglobulin or the early IV preparation supplied by this company.

Yours sincerely,

Associate Professor John B. Ziegler, FRACP

Department of Immunology/Allergy

Sydney Children's Hospital, Randwick

J.Ziegler@unsw.edu.au

\section{April, 1998 ;}

Since this letter was written, in July 1999 Victorian authorities reported a case of HIV transmission in contaminated blood. The NSW Department of Health investigates any claims of association between infectious diseases and immunoglobulin or other blood products. Suspected cases should be reported to the local public health unit. 